San Jose State University

SJSU ScholarWorks

Faculty Publications

Social Work

January 2013

\title{
International social work field placement or volunteer tourism? Developing an asset-based justice-learning field experience
}

\author{
Marie-Antoinette Sossou \\ University of Kentucky \\ Nicole Dubus \\ Wheelock College, nicole.dubus@sjsu.edu
}

Follow this and additional works at: https://scholarworks.sjsu.edu/social_work_pub

Part of the Social Work Commons

\section{Recommended Citation}

Marie-Antoinette Sossou and Nicole Dubus. "International social work field placement or volunteer tourism? Developing an asset-based justice-learning field experience" Journal of Learning Design (2013): 10-19. https://doi.org/10.5204/jld.v6i1.113

This Article is brought to you for free and open access by the Social Work at SJSU ScholarWorks. It has been accepted for inclusion in Faculty Publications by an authorized administrator of SJSU ScholarWorks. For more information, please contact scholarworks@sjsu.edu. 


\title{
International Social Work Field Placement or Volunteer Tourism? Developing an Asset-Based Justice-Learning Field Experience
}

\author{
Marie-Antoinette Sossou, $\mathbf{P h D}$, \\ Associate Professor \\ University of Kentucky, College of Social Work \\ Lexington, $\mathrm{KY}$ \\ msoss2@uky.edu
}

Nicole Dubus, MSW, PhD

Assistant Professor, Social Work

Wheelock College, Boston, MA

ndubus@wheelock.edu

\begin{abstract}
This paper examines a developing model for building an international social work placement that meets the needs of the host agency and community first. The paper addresses the challenges for social work departments to develop a strong learning environment while also keeping primary the needs of the host community and agency.
\end{abstract}

Keywords

Field placement, international, justice-based, social work, asset building

\begin{abstract}
Placement of social work students as interns in human service agencies is considered a core pedagogical element in social work education. Kilpatrick and Holland (1993) considered the infusion of field placement into social work education to be one of the most important components for preparing social workers for effective social work practice. Other social work educators supported this assertion by emphasising that without field instruction, social work education would be a mental exercise and lack hands-on training (Shawky, 1972). Sheafor and Jenkins (1982) believed that the purpose of field instruction is to provide a context for applied learning of the theories presented in-class to more effectively work with client populations, and Kadushin (1991) also believed that field instruction is often the most meaningful and memorable aspect of social work education. As a result, all social work students are mandated to complete specific hours of field placement to qualify to practice as professional social workers nationally and globally (CSWE, 2008).
\end{abstract}

International social work field placement in both developing and developed countries is a significant opportunity for social work students, both undergraduate and graduate, to enhance their personal and professional social work development. Exposing social work students to international internships in local social and human services organisations and other non-governmental organisations is essential in helping students to develop a greater sense of self-awareness, respect and appreciation of different cultural beliefs and practices of other people and cultures, and becoming conscious and cultural sensitive concerning issues of poverty and social injustice. NASW's Standards for Cultural Competence in Social Work Practice (2001) states that social workers shall have and continue to develop specialised cross-cultural knowledge and understanding about the history, traditions, values, family systems, and artistic expressions of major client groups that they serve. Also, they shall use appropriate methodological approaches, cross-cultural skills, and techniques that reflect their understanding of the role of culture in the helping process (NASW, 2001). Hence, exposing social work students to international field 
placements will provide opportunities for them to share and learn from different perspectives of social welfare policies and practices globally.

In response to a globalised and connected society, CSWE Educational Policy and Accreditation Standards (EPAS) (CSWE, 2008) has emphasised the importance of international content in the social work curriculum. For example, section 2.1.5 supports the advance of human rights and social and economic justice and affirms that "each person, regardless of position in society has basic human rights, such as freedom, safety, privacy, an adequate standard of living, health care, and education" As a result, social workers must recognise the global interconnections of oppression and become knowledgeable about the theories of social justice and strategies to promote human and civil rights (CSWE, 2008). The social work profession therefore has the mandate and the responsibility to respond to global social issues, challenges and problems by preparing social work students to become culturally responsive and interested in sharing their knowledge, skills and competencies with their global colleagues and also learn from their international field placements.

\section{Is it Volunteer Tourism or Helping?}

Global volunteer tourism is not a new phenomenon; however, it became popular during the founding of the British Volunteers Service Overseas in 1958 and the establishment of the United States Peace Corps in 1961 during the John F. Kennedy administration. According to Wearing "volunteer tourism combines travel with voluntary work by attracting individuals (students) that are seeking a tourist experience that is mutually beneficial, that will contribute not only to their personal development but also positively and directly to the social, natural and/or economic environments in which they participate" (2001, p. 1.).

Recently, despite increase in volunteer tourism activities globally and involving academic institutions, the issue has come under criticism for a number of reasons. For example, Birrell (2010 as cited in Voluntourist Newsletter 6) has criticised the rapid growth of volunteer tourism of the western developed world to the developing world as being "more about the self-fulfillment of westerners than the needs of developing nations." Other researchers have also found a number of volunteer tourism cases where experiences do not seem to encourage critical reflections about poverty (Simpson, 2004; Ver Beek, 2006 as cited in Voluntourist Newsletter 6). Additionally, other studies have suggested numerous factors that make volunteer tourism less beneficial to both the individual and the host community. These factors include: lack of knowledge by the volunteers to the issues of the community (Brown \& Hall, 2008), poor insight from the volunteer (Simpson, 2004), insufficient skills (Raymond \& Hall, 2008), lack of cultural awareness (McLeod, 2008), insufficient time to spend on a project (Roberts, 2004) or lack of clear intentions from the volunteer and less than clear goals from the community (Salazar, 2004). Therefore, as social work educators interested in international social work placements of our students, the question we have to pose and answer is who benefits more from these international placements abroad? Is it the students or the local communities that are involved in the partnership?

Social work students, perhaps more so than other disciplines engaged in field placements, have the potential to offer host communities concrete specialised skills. Social work students are trained in such skills as assessment, cultural awareness, systems theory, case management, crisis intervention, community organising, and other skills from which host agencies and communities could benefit. Most students embarking on an international placement have already had a previous, yearlong placement in a community agency setting as well as at least one academic year of social work instruction and bring with them, that experience and knowledge.

Designing programs and projects that involve the active participation of the host communities to ensure long-term sustainability should be an essential component of international placement and planning for social work students. This involvement of the host community is essential for maintaining social work ethical principle of self-determination and the establishment and respect for human relationships between the visiting students and the host communities. This approach is 
important in view of the limited financial resources faced by social services agencies in the developing countries. Careful attention should be paid to respecting the views, inputs and values of the host communities with regards to our own ethical standards. For effective collaboration and learning to take place, social work educators interested in study abroad or field practicum placement should engage in preparatory planning and pre-departure education programs to help their students to be ready to develop cultural appreciation and understanding of their host communities.

\section{Beyond Field Placement}

The criteria for effective social work placement involves: a) an on-going working relationship with the agency and stakeholders in the hosting community, b) a project or program where the students have the opportunity to provide concrete and useful services to the community, c) an environment that enhances the student's understanding of social work theory and practice, and d) social work staff who are able to appropriately supervise students (Lough, 2009; Twill Elpers, \& Lay, 2011).

With the increased interest in international field placements there is a need for effectively designed placements that address the competencies outlined by the CSWE as well as the values of social work. Hence this paper suggests that international field placements should embrace an asset-based justice-learning placement (Butin, 2007; Donaldson \& Daughtery, 2011). Butin (2007), who examines service learning within other academic disciplines, proposes a "justice-learning" model that challenges institutionalised field experiences. Cuban and Anderson (2007) draw from Butin in their conception of political service learning. Butin (2007) and Cuban and Anderson (2007) seek to develop field experiences that go beyond learning experiences for students that may address issues of social injustice to a method of "correcting power imbalances, taking the perspective of and advocating for marginalised groups, and harnessing resources for social change with universities as major change agents" (Cuban \& Anderson, 2007, p. 145). This approach views social problems from a systems perspective and attempts to make chances that are not focused on short-term individual solutions, but larger institutional changes. This view is consistent with social work values and pedagogical intention for field practice. However, international social work field placements warrant a more conscientious commitment to "justice learning". Such a justice learning perspective requires that the international field placement experience examines both the immediate presenting need and also the underlying societal issues.

Donaldson and Daughtery (2011) discuss an asset-based model of social justice in developing a service learning program. This model is based on a theoretical perspective of distributive justice. Distributive justice (Rawls, 1971) examines the criteria for the allocation of resources, paying close attention to the just distribution of resources. The asset-based model is also concerned with the expansion of human capabilities. The expansion of human capabilities focuses on the equal distribution and access to the resources and institutions needed to manifest each individual's true potential. As a theoretical base, the model is concerned with the distribution of resources as well as the supporting, and hindering, elements in society that determine how well those resources can be used.

As a service learning method, the asset-based model critically examines the roles and positions of the educational institution providing the service learning. In this model, the educational institution developing a service learning program self-evaluates its role in enhancing or detracting from the community it wishes to serve. Issues of: power, privilege, stereotypes, isolation, institutionalisation are addressed in ways that draw out the strengths, and challenge the limitations of the education institution that wishes to work with vulnerable community-based groups. An international field placement, drawing from this model, would raise these issues as the department develops the international field placements, designs the curricula, and executes the placements with the students. The students' work with the agency would be within the framework of these issues. 


\section{A Developing Model}

The following is based on an internship placement that occurred in Accra, Ghana in 2011 through the School of Social Work at the University of Kentucky. Six social work students, two MSW and four undergraduate students were originally placed at three different social services sites. One of the agencies was a governmental social welfare organisation and the remaining two were nongovernmental private social service agencies all located in the capital city of Ghana.

The sites chosen were in line with social work values of agencies that work with the most vulnerable populations and where there was social work supervision available. The initial intent was to provide students with valuable learning environments and to be of service to the agencies where the students were placed. There was much success in these placements and all the students reported profound and growing experiences. The agencies themselves reported positive experiences with the students. However, upon reflection, it appeared that the experience could be deepened with a shift in perspective. While maintaining high standards for a learning environment for social work students, the authors wished to enhance the placements by ensuring greater growth of knowledge for the students and a more concrete assistance for the agencies. It was decided that the next placement, 2012, would be developed with the asset-based justice learning model. The asset-based justice learning model draws from Donaldson \& Daugherty (2011) and Butin, (2007) and entails focusing the placement around the needs of the host community. Instead of the centralising question being "what is in the best interest of the student's learning?" the question becomes "what is in the best interest of the host community? What do they need from us?" To answer this question means not only to ask the host community, but to let the host define the problem and the solution. This model also necessitates that the question goes beyond the immediate need and into a wider perspective that includes long-range solutions to structural injustice.

\section{Ghana Field Placement}

An effective field placement cannot be established without an understanding of the community in which the students were placed. Ghana was chosen for a number of reasons: 1) Ghana is an English speaking country which makes it more accessible for students to immerse themselves into the culture; 2) Ghana is a stable country in Africa, having gained its independence in 1957 and continued to have peaceful elections, a growing economy, and a global economic presence; 3 ) Ghana has already established partnerships with universities from Canada, the United States, and the Netherlands. These previously established partnerships makes Ghana familiar with such arrangements, experienced in developing effective partnerships, and inviting of the benefits of these collaborations.

\section{Country Background}

Ghana has a population of nearly 25 million, more than 3 million in the city of Accra, its capital (Population Council, 2011). The country is divided into ten regions, (CIA, 2011). While the official language is English, it is not the primary language. Many speak regional languages, such as Twi, Ewe, and Ga. Almost half (49.3\%) of the population is from the ethnic group Akan, which has a strong matrilineal presence in its community structure. While reported statistically as $68.8 \%$ Christian and 15.9\% Muslim (CIA 2011), Ghana in practice is, as one resident noted, " $75 \%$ Christian, 25\% Muslim, and 100\% animistic". More Christians reside and practice in the southern regions while more Muslims live and practice in the northern regions.

Ghana has a long history of being exploited for its gold, ivory and people, first by the Portuguese in the late 1400's, followed one hundred years later by the Dutch, and then fifty years later by the English, Danes, and Swedes. By the late 1800's, British was firmly planted in Ghana, claiming it as the Gold Coast. In 1957 Ghana declared its independence through the leadership of its first president, Kwame Nkrumah (Gocking, 2005). Nkrumah's legacy stems from Ghana's independence, and branches out to Nkrumah's national pride and his opposition to neo- 
colonialism, and his ability to place Ghana on the international stage among other nations. His memorial, museum, park, and the Volta Dam which generates $75 \%$ of Ghana's energy are testaments to his importance to Ghana (CIA, 2011). Ghana is an old country with long cultural histories, and is young, 52 years, as a government. Its population is young as well, $36 \%$ of the population is below the age of 15 (Population Council, 2011), compared with $20 \%$ of the population of the United States. This is an often-stated concern among the social workers.

Needs

Ghana is a relatively young, independent nation with a young population. Literacy rates are low, and school attendance, especially by girls is poor (Tuwor \& Sossou, 2008). Ghana has three times the rate of HIV infection as does the rest of the world, $3 \%$ of those $15-49$ years old infected with HIV, compared to $1.2 \%$ of the rest of the world (Population Division of the Department of Economic and Social Affairs of the United Nations Secretariat, 2002). Ghana is a country rich in resources yet nearly $29 \%$ of its population live below the poverty line. Its poverty is severe; without public assistance, housing, accessible health care, those in poverty live on the streets, in corrugated tin huts, and cement block one-room homes with no plumbing, sewerage and electricity. Ghana has one Social Welfare Department that serves its ten regions, usually with one social worker in each region. The Social Welfare Department is in charge of all aspects of social service, i.e., medical social work, case management, family and children welfare, immigration and refugee services, child protection, shelter, and school social work. There are a number of NGOs that work to meet the needs that the Social Welfare Department cannot provide.

\section{Working Relationship}

To be an effective learning experience for the students, and a beneficial arrangement with the host community, a stable on-going relationship with members of the community is needed. The second author, a faculty member of the University of Kentucky, is a native of Ghana, a former faculty member of the University of Ghana, and a former social worker from Ghana's Department of Social Welfare. She has developed and maintained professional relationships with the University of Ghana's Department of Social Work, and with the Department of Social Welfare which covers many service locations throughout Ghana.

\section{Pre-Departure Preparations}

This preparation involves application and selection procedures through personal essays expressing the reasons for choosing to study abroad and performing international social work field practicum for six weeks in a developing country, Ghana. One criterion for acceptance into this program is the completion of at least one social work field practicum for both undergraduate and graduate students in the United States before their departure to Ghana. The rationale for this criterion is to make sure students have the basic and generalist practice skills of social work such as interviewing, assessment, knowledge of the ethical issues, problem solving and intervention skills. Assignments are another form of pre-departure preparation for students. These assignments involved reading assignments and answering of assigned questions concerning selected articles about concepts, techniques and practice of community and social development theories to prepare students about the understanding and application of the various models of community and social development from the developing countries' perspectives.

Also, students were prepared intellectually by providing them with face-to-face historical background information about the political, social, economic, educational, religious, and cultural issues of the country of study. This presentation provided the students the opportunity to express their views, ask questions about their fears, anxieties, and also cleared their misinformation and doubts as well. Additionally, students were given the opportunity to watch and write a two-page review of a selected video documentary that depicts socio-economic/cultural portrayal about a social issue/problem in the country. This video was selected based on literal reviews and popularity of the documentary. Finally, pre-departure preparation also included providing information to students concerning everyday issues such as acquiring passport, visas, travel 
insurance, immunisations, clothing, local currency, cultural shock, safety, local transportation, and accommodation among others.

\section{Pre-Departure Preparation for the Host Country}

Preparation for the host country is equally important for a smooth transition of the students' international experience. This preparation involved finding and identifying social service agencies that were interested in hosting and supervising social work students for the specific time frame. The second author, originally from Ghana used her old connections with the Department of Social Welfare to find placement for students within the social welfare system in Ghana. Other nongovernmental organisations were identified and contacted and they also agreed to accept social work students for placement. In the end, more social services agencies were willing and ready to accept international students than students available for international placement in Ghana. It is important to acknowledge that having prior information about the various agencies willing to accept students for placement made it possible for students to make their choices and personal connections to the agencies by contacting and introducing themselves to the agencies before their physical arrival in Ghana and the internet was very useful in this regard.

Additionally, it is important to find local resource persons to provide local orientation to students concerning development of social work services, social work practice in Ghana and information of acceptable cultural practices and safety issues for students during their stay in the country. Finding decent and affordable housing and transportation for the students is another pre-departure preparation in the host country. The preparation involved contacting a number of hostels and private transport services to find out about their facilities, services, prices, availability and accessibility to the various agencies, shopping centres and downtown city centre. Apart from the educational aspect of the international social work field practicum being the core purpose of the trip, preparations had also been made for students to visit a number of tourist sites to add to the socio-cultural educational piece of the trip. Therefore, contacts had to be made to visit various sites such as the slave castles, local craft markets, beaches and national rain forest and monkey sanctuary all within a day's travelling itinerary.

\section{Problems and Challenges}

Even though English language is the official language in Ghana, the language barrier is a major challenge and a problem for all international students as there are so many local dialects spoken by the local people. This puts students at a disadvantage for effective interpersonal communication with illiterate local people and with some of the adult clients and the children. Another challenge faced by the students was understanding and making sense of the causes, consequences and dynamics of the different forms of extreme poverty, oppression, human rights abuses and social injustices experienced by the members of the host communities without being judgmental. For example, seeing issues and problems with the western lens, and the western models of interventions and training could lead to superficiality and lack of understanding of issues in the host culture and its social systems. According to Dominelli (2005), this reinforces misconceptions and cultural stereotypes as well as reproducing social injustice, inequities and oppressive relationships.

Transportation and commuting from the hostel to the various placement locations was another challenge. In the United States, these students were used to getting into their individual cars and driving to wherever they wanted to go on their without any problem. However, in Ghana, that luxury was non-existent. The program coordinator, one of the authors of this paper, hired a van and a driver for the daily commute of the students from their hostel to their various social services agencies. The commute in the mornings and evenings was between one to two hours due to the heavy traffic congestion in the city. This challenge could be addressed as part of the "cumbersomeness of poverty" and used as a teaching opportunity to discuss classism and ease of access. It was also an informative commute as they often spent the bulk of the time in deadlock traffic in the centre of Accra, allowing them to experience the vendors, residents, and movement of goods and service in the city. This challenge could also be lessened by choosing housing that is 
nearer to the placements. There are a number of options for housing that may work well. Besides adjusting to the new and different life style in Ghana in terms of the culture, climate, traffic conditions and housing, the students were also adjusting to being immersed in poverty, social inequalities, oppression and discrimination against children, women and physically disabled people. These conditions were completely foreign to their own personal experiences.

Over-expectation and conflicted professional ethical practice was another challenge that confronted the students during their placement. The students were surprised to observe that client self-determination, privacy and confidentiality and all the other ethical values they were used to were not fully observed or practiced effectively as they expected. The students' daily or weekly assignments were important for reflection and discussion on their experiences, frustrations, inadequacies and other limitations. For example, students who expressed their interest in working with children and were assigned to a children's home spent only one day at this placement due to being overwhelmed, frustrated and angered by the hostility and lack of professionalism displayed by the local staff. As a result, the field coordinator must be flexible and understanding of the cultural differences and assist the students to process these problematic challenges in a timely manner by finding alternative placements for the affected students.

Furthermore, there is the tendency for some student interns to play the passive role of an observer/foreigner instead of accepting the challenge to display their social work skills and knowledge when requested by the host agency to carry out a function. On the other hand, host agencies have to be constantly reminded that the student interns have social work skills of interviewing, assessment, problem-solving group work and case management that they could tap for their daily activities. This situation leads to underutilisation of both students' expertise and agencies' human resources. An informal interview with the students revealed that they felt grateful for the experience, and that their social work education was greatly enhanced, and that this experience was invaluable to them. They all stated in various ways that they grew in cultural competence. As one student stated, "I was told I would feel culture shock when I got here. But I didn't. I didn't when I saw where they lived, what they ate, nothing. I didn't have cultural shock until I sat in on a session."

\section{The Way Forward}

It is evident that international placements of students offer a significant learning opportunity. However, while these students appeared to gain a greater depth of academic knowledge about the agencies and services provided to client populations, they were not fully involved in the planning and execution of the programs they worked on. These students, like many international students, were placed in already planned programs or services as mostly observers instead of active participants. The host agencies under-utilised the skills and knowledge base of the students. The potential to address social injustice in the immediate and long-term is compromised by the placement process. To encourage students to challenge their dominant western paradigms and confront traditional views of social problems, they should become equal and active participants by working directly with the members of their host client populations.

We suggest involving students in an asset-based justice learning model where the students and the host agencies and communities work together to meet the needs of the community while engaging students in their own learning. Therefore, to become effective international social work interns, they have to combine their professional western knowledge with the local knowledge and traditional approaches to helping, and the best approach is to enter into partnership with the local clients/communities to work together to meet their mutual goals: providing concrete services determined by the host agencies as helpful, addressing immediate and underlying social injustice by building on the assets of the host community, and engaging the students in the learning and serving process. Hence, the application of the asset-based social justice model should be the way forward. For the field placement to take a stand for social justice, it should be proactive in engaging the host communities in the planning of projects that will be beneficial to both the community and the international social work students. 
According to Marullo and Edwards (2000) service learning based on social justice engages students in ways that help communities develop long-term structural changes. Brown (2001) identified a five-step process for establishing service learning relationships that sustains programs beyond single projects and puts diverse community members in direct communication with each other. These five approaches were 1) initiating contacts, 2) holding workshops to generate goals; 3 ) reporting on partnerships, 4) collectively assessing projects, and 5) creating a resource that would document the collaboration in ways that will be useful in sustaining the partnership. Based on this approach, in anticipation of a future international field placement in Ghana, collaborative efforts are being made with a number of agencies in Ghana to assist them to identify projects that are important to their local client systems. A refugee camp with multiple socio-cultural and health issues is being considered, as well as a domestic violence NGO that provides social education, counseling, and shelter for victims of domestic violence and rural community development organisation that works with rural people to develop their socio-economic resources in Ghana.

In a traditional approach for developing a field experience, these placement opportunities would be coordinated with a faculty member of the social work department. The agency would consent to having interns, and would find duties to perform that would be appropriate for social work students while also benefiting the agencies. In the asset-based justice learning model, the process is expanded to include the active participation of the students with the client systems in engaging and developing the strengths of the members and community to empower them to make lasting changes. Once an agency is identified, the faculty member and the agency enter into discussion about identifying a local project based on participatory engagement and principles of empowerment and ownership and capacity-building that would be beneficial to the client systems and the students. The faculty member facilitates the agency's understanding of the resources and skills the students can offer.

The students are instructed on the systemic injustices within the community. Once a specific project is identified and agreed upon, the students are informed about the project and are helped to start the preliminary planning for the project before departing on the international placement. Working with faculty, the students research and develop the resources the students will be providing. Once on-site, the students will work closely with the agency and the clients to execute the project. It is possible that this could be a multi-year process that allows future student interns to continue the project. Faculty will guide the students and the project, incorporating instruction to deepen the students' knowledge of systemic injustices, cultural issues, and skills.

This proposed asset-based social justice model will be executed in the summer of 2012 with a new group of social work students from the College of Social Work, University of Kentucky who would be interested in doing their second field placement practicum in Ghana. The expected outcome of this placement design is to ensure that the international field placement is not considered as volunteer tourism but a collaborative relationship that provides concrete service to the host agencies and the communities in such a manner that addresses immediate and long-term social injustice. By doing so, the students' learning will be enriched, and the needs of the host communities will be addressed by strengthening the capacity-building of the community to counter injustice through their own assets.

An effective asset-based program will focus on the strengths and aspirations of the client systems and their communities. Additionally, the asset-based program fits in well with the practice of community development projects that are very useful and practical in most rural communities across Ghana. Numerous researchers (Batten, 1965; Biddle \& Biddle, 1965; Brokensha \& Hodge, 1969; Dore \& Mars, 1981; du Sautoy, 1958) have described community development as a process that seeks to combine local community resources with those of external agents to enhance standards of living and to promote community integration. The notion of community resources involves the participation of ordinary people in decision making and the mobilisation of their effort, time, and labor for development projects. Similarly, the external agents in this case include the social work students, their skill sets, and resources, and paraprofessional community development workers and the sponsoring agency, either the governmental social welfare department or the non-governmental organisation, which will administer the community 
development services that will be responsible for the provision of material, technical, and social services to the host community.

The practical process of community development programs is based on the notions of participation, democratic decision making, self-determination, and social integration. Therefore, for the asset-based justice project to be successful, the international field placement students must be fully engaged in participation with the local people/clients and the host communities in the process of making democratic decisions about program priorities and the way they want projects to be implemented for the better benefit of all. The asset-based project will be subjected to systematic evaluation to make sure the intended outcomes have been achieved. This will be carried out through regular data collection from all the participants, the students, the host agencies and the host communities/client groups to ensure that basic principles of mutual communication, reciprocity and mutuality and respectful relationships and global ethical guidelines have been achieved in the process.

\section{Conclusion}

According to Midgley (1990), international social work is a "two way street" that each party is a learner in partnership. Secondly, "social work is concerned with social change, social justice, empowerment and problem solving and the intersection between individuals and their environments" (International Federation of Social Workers, 2004). Hence, the guiding principle behind the asset based model is an appreciation of local values, and the inseparable relationship between human existence and the environment. It is informed by a reciprocal strengths-based approach that creates the feeling that all participants involved are treated equally and benefiting from the process. Additionally, the asset-based approach to international social work education ensures reciprocity and the development of long-term programs, personal relationships that would facilitate mutual participation and respect for cultural norms and inter-cultural learning to encourage students to confront their own ethnocentricities and prejudices. Also, it helps to reduce the potential of the social work profession to become culturally irrelevant. The purposes of international social work are to promote global social justice and human well-being and to ensure the ongoing relevance of locally based practice by calling attention to global realities that affect local conditions (Healy, 2012). Therefore designing appropriate culturally relevant programs based on the principles of mutuality and reciprocity and appreciation of cultural diversity should be the goal for international social work field placement.

\section{References}

Batten, T. R. (1965). The human factor in community development. London: Oxford University Press.

Biddle, W., \& Biddle, L. (1965). The community development process. New York: Holt, Reinhart \& Winston.

Birrell, I. (2010, November 14). Before you pay to volunteer abroad, think of the harm you might do. Retrieved from http://www.voluntourism.org/news-studyandresearch64.htm

Brokensha, D., \& Hodge, P. (1969). Community development: An interpretation. San Francisco, CA: Chandler.

Brown, D. M. (2001). Pulling it together: A method for developing service-learning and community partnerships based in critical pedagogy. Corporation for National Service.

Brown, F., \& Hall, D. (2008). Tourism and development in the Global South: The issues. Third World Quarterly, 29(5), 839-849

Council on Social Work Education, (2008). Educational policy and accreditation standards. Alexandria, VA: CSWE. 
Dominelli, L. (2005). Social work futures: Crossing boundaries, transforming practice. Basingstoke, UK: Palgrave Macmillan.

Dore, R., \& Mars, Z. (1981). Community development. London: Croom Helm.

du Sautoy, P. (1958). Community development in Ghana. London: Oxford University Press.

Healy, L.M. (2012). Defining international social work, In L.M. Healy \& R.J Link (Eds.), Handbook of international social work: Human rights, development, and the global profession (pp. 9-15). Oxford: Oxford University Press.

Kadushin, A. (1991). Introduction. In D. Schneck, B. Grossman \& U. Glassman (Eds.), Field education in social work: Contemporary issues and trends (pp.11-12). Dubuque, IA: Kendall/Hunt Publishing Company.

Kilpatrick, A.C., \& Holland, T.P., (1993). Management of the field instruction program in social work education, Journal of Teaching in Social Work, 7, 123-135.

Marullo, S., \& Edwards, B. (2000). From charity to justice: The potential of university community collaboration for social change, American Behavioral Scientist (43), 895-912.

McLeod, H. (2008). Humanitarian emergencies: Do volunteers help or hinder? Just change. Critical Thinking on Global Issues, 11, 8-10.

Midgley, J. (1990). International social work: Learning from the third world. Social Work, 35(4), 295-301.

NASW (2001). NASW Standards for cultural competence in social work practice. Washington, DC: NASW.

Raymond, E.M., \& Hall, C.M. (2008). The development of cross-cultural (mis)understanding through volunteer tourism. Journal of Sustainable Tourism, 16(5), 530-543.

Roberts, T. (2004). Are western volunteers reproducing and reconstructing the legacy of colonialism in Ghana? An analysis of the experiences of returned volunteers. Unpublished Master's thesis, University of Manchester, UK.

Salazar, N. (2004). Developmental tourists vs. development tourism: A case study. In A. Raj (Ed.), Tourist behavior: Psychological perspective (pp. 85-107). New Delhi, India: Kanishka.

Shawky, A. (1972). Social work education in Africa, International Social Work, 15, 3-16.

Sheafor, B., \& Jenkins, L (1982). Quality field instruction in social work. New York: Longman.

Simpson, K. (2004). Doing development: The gap year, volunteer-tourists and a popular practice of development. Journal of International Development, 16, 681-692.

Ver Beek, K. (2006). The impact of short-term missions: A case study of house construction in Honduras after Hurricane Mitch. Missiology: An International Review, 34(4), 477-496.

Wearing, S. (2001) Volunteer tourism: Experiences that make a difference. Oxon: CABI. 